\title{
ARE THERE DIFFERENCES IN MOTIVES BETWEEN PARTICIPANTS IN INDIVIDUAL SPORTS COMPARED TO TEAM SPORTS?
}

\author{
Arne Martin Jakobsen \\ University of Nordland, Department of Sport, \\ Address: NO-8049 Bodø, Norway \\ Phone: 75517932 \\ E-mail: arne.jakobsen@uin.no
}

\begin{abstract}
The aim of this study was to explore which motives dominate among adolescents when it comes to participation in individual versus team sports. We expected that intrinsic motives will dominate in both groups. We also had a hypothesis that those who compete in individual sport will have higher scores on intrinsic and lower on extrinsic motivation than those in team sport. We also expected that intrinsic motives would explain why they had chosen individual sports instead of team sport. The participants were 78 athletes, 39 in team sports and 39 in individual. Participants' motives were assessed with the Motives for Physical Activity Measure - Revised (MPAM-R). The extrinsic motive "fitness" had highest score in both groups, followed by the intrinsic motives "interest/enjoyment" and "competence". The only motive with a difference between team and individual sport was the intrinsic motive interest/enjoyment. The participants in team sport had a higher score on interest/enjoyment than those in individual sport. We conducted a regression analyze to explain why pupils chose individual instead of team sports. "Interest/enjoyment" had an explanation when we included this as a single independent variable. If they participated in team sport they had a higher score on the intrinsic motive "interest/enjoyment". When we included all the motives none of them had an explanation. In conclusion we could not find any differences in motives for participation in team versus individual sport. We also only partly found support for the assumption that adolescents mostly are intrinsic motivated for participating in sport.
\end{abstract}

Key words: Motivation, self determination theory, individual sports, team sports 


\section{Introduction}

Sport is for most participants, intrinsically motivated. Exercisers are more likely to be motivated by extrinsic motives such as improving one's appearance. Moreover the more amateur level of sport, the more the motives for engaging in it were intrinsic. Sports are more often played for enjoyment and interest than for extrinsic goals (Vallerand \& Losier, 1999; Verloigne et al., 2011). Contexts fostering autonomy and perceived competence enhance enjoyment and sustained motivation (Chatzisarantis, Hagger, Biddle, \& Karageorghis, 2002; Hagger \& Armitage, 2004; Hagger, Chatzisarantis, Culverhouse, \& Biddle, 2003; Hagger, Chatzisarantis, \& Harris, 2006). Sustained exercise is most likely when a person has both well internalized extrinsic motivation and intrinsic motivation (Duncan, Hall, Wilson, \& Jenny, 2010; Ryan \& Deci, 2007; R. M. Ryan \& Deci, 2002; Smith, Ntoumanis, Duda, \& Vansteenkiste, 2011; Vlachopoulos, Ntoumanis, \& Smith, 2010).

A controversial but also interesting issue is the impact of competition on intrinsic motivation. Competitive contexts have both informational and controlling aspects; this is according to the cognitive evaluation theory (Deci \& Ryan, 1985). Competitive environments can offer optimal challenge and competence feedback. But at the same time competition often includes controlling components, as people feel pressured to win (Bartholomew, Ntoumanis, Ryan, \& Thøgersen-Ntoumani, 2011; Ryan \& Deci, 2007). Participants pressured to win can lose intrinsic motivation even if they win, while those competing without pressure don't (Camacho, Soto, González-Cutre, \& Moreno-Murcia, 2011; Gillet, Vallerand, Amoura, \& Baldes, 2010; Reeve \& Deci, 1996; Ryan \& Connel, 1989; Ryan \& Deci, 2007). Even those who do not come out on top, can maintain intrinsic motivation in the absence of controlling pressure to win (Vansteenkiste \& Deci, 2003).

It is more than intrinsic motivation for engaging in sport and exercise. People have many extrinsic reasons for engaging, from health reasons to desire of recognition. Moments of flow are often separated by long periods of hard work. Sometimes this practice itself is not inherently enjoyable (Ericsson, 2003). Within self-determination theory there are two broad classes of nonintrinsic motivation. This is extrinsic motivation which is behavior motivated by expected outcomes not inherent in the activity itself. The other one is amotivation which is not having either energy directed toward action or intention. People are viewed as typically having multiple motives, both extrinsic and intrinsic (Hagger \& Chatzisarantis, 2008; Lonsdale, Sabiston, Taylor, \& Ntoumanis, 2011; Ryan \& Connel, 1989). 
With the satisfaction of the needs of autonomy, competence and relatedness we will achieve an optimal motivational function. This is called the basic psychological needs theory. Cognitive evaluation theory describes the environmental contingencies that lead to the adoption of intrinsically or extrinsically motivated behavior. Last the organismic integration theory identifies the quality of motivation on a scale of perceived locus of causality. These causalities are ranged from highly autonomous to highly controlling (Edmunds, Ntoumanis, \& Duda, 2007; Markland \& Ingledew, 2007 ; McLachlan \& Hagger, 2011; Ryan \& Deci, 2007).

Extrinsic motivation when it is controlling/low autonomy, the locus of causality is named external regulation. People are engaged in physical activity because of external reinforcement such as gaining rewards or avoiding punishment. A person could also be motivated out of introjected regulation which is defined from avoiding external sources of disapproval, or gaining externally referenced approval. Introjection is based on selfesteem-related contingencies and ego involvements (McLachlan \& Hagger, 2011; Ryan \& Deci, 2007; Ryan, Koestner, \& Deci, 1991). Both external and introjected regulations are controlling forms of motivation based on controlling the self by pressure and contingencies.

When a person behaves through identified regulation, extrinsic motivation can be relatively autonomous. Here the person engages in the extrinsic action because of identification with the purpose and value. This can be values such as learning new skills. An even more autonomous level is called integrated regulation. Here behaviors are fully integrated into the repertoire of behaviors that satisfy psychological needs of autonomy, competence and relatedness. Thus still it is not fully intrinsic motivated. The highest level of intrinsic behavior we only do for enjoyment, pleasure and fun. There are no rewards, or discernible reinforcements involved (Bagoien \& Halvari, 2005; Hagger \& Chatzisarantis, 2007).

Autonomous regulation is associated with action and maintenance of change for exercise (Edmunds, et al., 2007; Landry \& Solomon, 2004), exercise related self-esteem (K. B. Wilson \& Rodgers, 2004), greater physical fitness (Stanley, Cumming, Standage, \& Duda, 2012; Wilson, Rodgers, Blanchard, \& Gessell, 2003), more frequent self-reported exercise behavior (Wilson, Rodgers, \& Fraser, 2002), and more positive attitude toward exercise (Stanley, et al., 2012; Wilson, et al., 2003). Perceived autonomy support from friends is positively associated with identified regulation an intrinsic motivation (Wilson \& Rodgers, 2004). It is also reported that perceived autonomy support from the exercise instructor 
positively predicted relatedness, autonomy, competence need satisfaction and intrinsic motivation (Edmunds, et al., 2007).

Psychological need satisfaction is positively correlated with identified and introjected regulation and intrinsic motivation (Stanley, et al., 2012; Stuart, 2013; Wilson, et al., 2002). Competence need satisfaction, introjected and identified regulations positively predicted strenuous exercise behavior, while external regulation is a more negative predictor of strenuous exercise behavior. Competence need satisfaction also have both direct and indirect effects on behavioral investment (Edmunds, et al., 2007).

The aim of this paper is to explore which motives dominate among adolescents when it comes to participation in individual versus team sports.

We expect that intrinsic motives will dominate in both groups (Quested \& Duda, 2011; Stanley, et al., 2012). We also have a hypothesis that those who compete in individual sport will have higher scores on intrinsic and lower on extrinsic motivation than those in team sport. This expectation builds upon the assumption that there is less autonomy in team sports because the more participants the coach have to deal with the harder it is to give each participant the possibility to make their own choice (Stanley, et al., 2012; Wilson, et al., 2002; Wilson, et al., 2003). When you are part of a team it is more difficult to evaluate your personal competence and the psychological need satisfaction will be less (Chatzisarantis, Hagger, \& Smith, 2007; Edmunds, et al., 2007).

We also expect that intrinsic motives will explain why pupils chose individual rather than team sports (Patrick \& Canevello, 2011; Ryan \& Deci, 2007).

\section{Method and Participants}

The participants were 78 athletes in four different sports, handball (11), football (soccer 29), gymnastic (12) and track and field (28). It was 26 boys and 54 girls from $13-19$ years old (mean 14.3). We asked the parents about permission for those under 15. The only inclusion criteria was if they competed in individual or team sport.

Procedure. Data were collected during one month in the spring of 2013. The language of the questionnaire was Norwegian. The questionnaire has been translated, and validated into Norwegian in an earlier study (Brislin, 1970, 1986). We collected the data just after a training session for all participants.

Measure.Participants' motives were assessed with the Motives for Physical Activity Measure - Revised (MPAM-R) (Ryan, Frederick, Lepes, 
Rubio, \& Sheldon, 1997). The scale consists of a total of 30 items assessing five different motives for participating in physical activities.

Fitness ( 5 items) refers to being physically active out of the desire to be physically healthy and to be strong and energetic ("Because I want to be physically fit"). Appearance (6 items), assesses being physically active in order to become more physically attractive, to have defined muscles, to look better, and to achieve or maintain a desired weight ("Because I want to lose or maintain weight so I look better"). Competence ( 7 items), refers to being physically active because of the desire just to improve in an activity, to meet a challenge, and to acquire new skills ("Because I like engaging in activities that physically challenge me"). Social (5 items), refers to being physically active in order to be with friends and meet new people ("Because I enjoy spending time with others doing this activity"). Interest/enjoyment ( 7 items) measures being physically active just because it is fun, makes you happy, and is interesting, stimulating, and enjoyable ("Because I like the excitement of participation").

The questions are rated on a 7-point Likert scale, from one (not at all true for me) to 7 (very true for me). We also registered if they participated in individual or team sport.

Analysis. Data were analyzed using SPSS (Version 20.0). In the section describing the sample, ANOVAs were applied to determine sample differences. For multivariate associations of the choice between team- and individual sport regarding the motivational scales, multivariate analyses of variance (MANOVA) were applied. Significant main effects were followed up using one-way analyses of variance (ANOVA). Effect sizes are reported using Cohen's $d$ and partial eta- square $\eta^{2}$. Cohen defined effect sizes as "small, $d=.2$, " "medium, $d=.5$," and "large, $d=.8$ " (Cohen, 1988).

\section{Results}

Preliminary data analysis. Data were screened according to the recommendations of Hair, Black, Babin and Anderson (2009). Examination of the assumptions associated with regression analyses (homoscedasticity, linearity and normality) suggests that there were no particular problems on the data. Both homoscedasticity and linearity assumptions were tenable.

To explore whether the data were marked by multicollinearity, both tolerance and variance inflation were examined. No problems were found, since the obtained values are within acceptable values (Hair et al. 2009).

Reliability analysis and descriptive statistics. Internal consistency estimates (Cronbach's alpha) of the MPAM-R subscales were computed. 
The reliability analyses indicate that internal consistency coefficients were good. All coefficients were greater than 0.79 for all multi-item scales.

The motive with the highest score in the whole sample was fitness with a mean score at $5.97(\mathrm{SD}=.83)($ team $\mathrm{m}=6.10, \mathrm{SD}=8.3$; individual $\mathrm{m}=5.84$, $\mathrm{SD}=8.2$ ), followed by interest/enjoyment (total $\mathrm{m}=5.95 \mathrm{SD}=.81$; team $\mathrm{m}=6.14, \mathrm{SD}=.75$; individual $\mathrm{m}=5.74, \mathrm{SD}=.84$ ), competence (total $\mathrm{m}=5.82$, $\mathrm{SD}=.83$; team $\mathrm{m}=5.99, \mathrm{SD}=.90$; individual $\mathrm{m}=5.62, \mathrm{SD}=.71$ ), social (total $\mathrm{m}=4.46, \mathrm{SD}=1.55$; team $\mathrm{m}=4.60, \mathrm{SD}=1.61$; individual $\mathrm{m}=4.31$, $\mathrm{SD}=1.47$ ) and last appearance (total $\mathrm{m}=4.18, \mathrm{SD}=1.23$; team $\mathrm{m}=4.36$, $\mathrm{SD}=1.29$; individual $\mathrm{m}=3.98, \mathrm{SD}=1.16$ ). There are significant difference (.01) in mean score between all the motives except fitness and competence, fitness and interest and appearance and social. Between competence and interest the difference was significant at $5 \%$ level.

Differences in motives between team and individual sport. Adolescents in both team and individual sport seem to score high on intrinsic motives like interest/enjoyment and competence. They also have high score on fitness which is an extrinsic motive. Both groups have a low score on appearance as expected. The last motive social has a relatively low score in both groups. The only motive where statistical differences appeared between the two groups is interest/enjoyment. The participants in team sport scored significant higher on interest/enjoyment $\left(5 \%\right.$ level, $\eta^{2}=.35$ and $\left.=.51\right)$ than those in individual sport. Also competence was close of being significant at 5\% level (sign .057). Those in team sport scored higher than the individual.

Regression analysis. One hierarchical regression analysis was conducted to examine how extrinsic and intrinsic motives predict the variable team or individual sport. We did an analysis with 5 different models (Tab. 1).

Table 1

5 models of hierarchical regression analyses predicting "team versus individual sport" from MPAM-R Subscale

\begin{tabular}{|l|c|c|c|c|c|}
\hline & $\begin{array}{c}\text { Model 1 } \\
\text { St.beta }\end{array}$ & $\begin{array}{c}\text { Model 2 } \\
\text { St.beta }\end{array}$ & $\begin{array}{c}\text { Model 3 } \\
\text { St.beta }\end{array}$ & $\begin{array}{c}\text { Model 4 } \\
\text { St.beta }\end{array}$ & $\begin{array}{c}\text { Model 5 } \\
\text { St.beta }\end{array}$ \\
\hline Interest/enjoyment & $-.252^{*}$ & -.214 & -.210 & -.226 & -.231 \\
\hline Fitness & & -.164 & -.162 & -.107 & -.112 \\
\hline Comeptence & & & -.007 & -.004 & -.004 \\
\hline Appearence & & & & -.096 & .106 \\
\hline Social & & & & & .022 \\
\hline Adjusted R & .048 & .059 & .043 & .033 & .017 \\
\hline F value & $4.298^{2}$ & 2.974 & 1.951 & 1.545 & 1.219 \\
\hline $\begin{array}{l}\text { Sign. F change } \\
\mathrm{N}=78\end{array}$ & .045 & .197 & .974 & .535 & .901 \\
\hline
\end{tabular}

**sign.01 level, * sign .05 level 
The only model with a significant explanation on the dependent variable "individual or team sport" was where "interest/enjoyment" was the only independent variable included. Those who competed in team sports had a high score on "interest/enjoyment". This model explained only $5 \%$ of the variance and was significant at the $5 \%$ level. When we included the other variables none of them had an explanation on the dependent variable.

\section{Discussion}

Our first hypothesis was that intrinsic motives would dominate in both individual and team sports (Quested \& Duda, 2011; Stanley, et al., 2012). We only partly found support for this. The extrinsic motive "fitness" had the highest score in both groups, followed by the intrinsic motives "interest/enjoyment" and "competence".

Next we expected that those who competed in individual sport would have higher scores on intrinsic and lower on extrinsic motivation than those in team sport. We had an assumption that there was less autonomy in team sports because the more participants the coach have to deal with the harder there is to give each participant the possibility to make their own choice ( Stanley, et al., 2012; Wilson, et al., 2002; Wilson, et al., 2003). We did not find any support for our hypothesis. The only motive with a difference between team and individual sport was the intrinsic motive "interest/enjoyment". The difference was actually the other way than we expected. The participants in team sport had a higher score on interest/enjoyment than those in individual sport. The same result appeared at the intrinsic motive competence but was not significant. We can therefore discard our hypothesis.

Finally we had an assumption that intrinsic motivation would explain why adolescents choose individual sports instead of team sports (Patrick \& Canevello, 2011; Ryan \& Deci, 2007). When we included all of the motives none of them had any explanation regarding the dependent variable "team versus individual sport". "Interest/enjoyment" had an explanation when we included this as a single independent variable. If they participated in team sport they had a higher score on the intrinsic motive "interest/enjoyment. Our hypothesis is therefore rejected.

Limitations of the study. There are some limitations of this study that should be considered. The number of participants in the study could have been extended. Only 80 participants took part. There are also more girls than boys in the study and results might have been different if we had included more boys. 
Future research perspectives. Future research in this area could look into differences between boys and girls. Are there any sex differences when it comes to participating in team or individual sports?

The fact that motivation seems to change with age makes it interesting to look into different age groups to find out which motives dominate at different ages.

\section{Conclusions}

In this study, we could not find any differences in motives for participation in team versus individual sport. Furthermore, we only partly find support for the assumption that adolescents mostly are intrinsic motivated for participating in sport.

\section{References}

1. Bagoien, t., E., \& Halvari, H. (2005). Automus motivation: Involvement in physical activity and percieved sport competence: Structural and mediator models. Perceptual and Motor Skills 100, 3-21.

2. Bartholomew, K. J., Ntoumanis, N., Ryan, R. M., \& Thøgersen-Ntoumani, C. (2011). Psychological need thwarting in the sport context: Assessing the darker side of athletic experience. Journal of Sport and Exercise Psychology, 33(1), 75-102.

3. Brislin, R., W. (1970). Back-Translation for Cross-Cultural Research. Journal of Cross-Cultural Psycholog, 1, 185-216.

4. Brislin, R., W. (1986). The Wording of Translation of Research Instruments. In W. J. Lonner \& J. W. Berry (Eds.), Field Methods in Cross-Cultural Research (pp. 137-164): Beverly Hills: Sage.

5. Camacho, Á. S., Soto, C. Á., González-Cutre, D., \& Moreno-Murcia, J. A. (2011). Motivational factors and autotelic experience in physical exercise: An explanatory model. Factores motivacionales y experiencia autotélica en el ejercicio fisico: Propuesta de un modelo explicativo, 10(1), 125-136.

6. Chatzisarantis, N. L. D., Hagger, M. S., Biddle, S. J. H., \& Karageorghis, C. (2002). The cognitive processes by which perceived locus of causality predicts participation in physical activity. Journal of Health Psychology, 7(6), 685-699.

7. Chatzisarantis, N. L. D., Hagger, M. S., \& Smith, B. (2007). Influences of perceived autonomy support on physical activity within the theory of planned behavior. European Journal of Social Psychology, 37(5), 934-954.

8. Cohen, J. (1988). Statistical power analysis for the behavioral sciences (2nd ed.). Hillsdale, NJ: Lawrence Earlbaum Associates.

9. Deci, E. L., \& Ryan, R. M. (1985). Intrinsic Motivation and SelfDetermination in Human Nature. New York: Plenum Press.

10. Duncan, L., R., Hall, G. R., Wilson, P. M., \& Jenny, O. (2010). Exercise motivation: a cross-sectional analysis examining ats relationships with 
frequency, intensity, and duration of exercise. International Journal of Behavioral Nutrition and Physical Activity, 7, 1-7.

11. Edmunds, J., Ntoumanis, N., \& Duda, J. L. (2007). Perceived Autonomy Support and Psychological Need Satisfaction in Exercise. In M. S. Hagger \& N. L. D. Chatzisarantis (Eds.), Intrinsic Motivation adn SelfDetermination in Exercise and Sport: Human Kinetics.

12. Ericsson, A. K. (2003). Development of Elite Performance and Deliberate Practice. In J. L. Starkes \& A. K. Ericsson (Eds.), Expert Performance in Sports, Advances in Research on Sport Expertise: Human Kinetics.

13. Gillet, N., Vallerand, R. J., Amoura, S., \& Baldes, B. (2010). Influence of coaches' autonomy support on athletes' motivation and sport performance: A test of the hierarchical model of intrinsic and extrinsic motivation. Psychology of Sport and Exercise, 11(2), 155-161. doi: 10.1016/j.psychsport.2009.10.004

14. Hagger, M. S., \& Armitage, C. J. (2004). The influence of perceived loci of control and causality in the theory of planned behavior in a leisure-time exercise context. Journal of Applied Behavioral Research, 9(1), 45-64.

15. Hagger, M. S., \& Chatzisarantis, N. L. D. (2007). Advances in selfdetermination theory research in sport and exercise. Psychology of Sport and Exercise, 8(5), 597-599.

16. Hagger, M. S., \& Chatzisarantis, N. L. D. (2008). Self-Determination Theory and the psychology of exercise. International Review of Sport and Exercise Psychology, 1(1), 79-103.

17. Hagger, M. S., Chatzisarantis, N. L. D., Culverhouse, T., \& Biddle, S. J. H. (2003). The processes by which percieve autonomy support in physical education and promotes leisure-time physical activity intentions and behavior: A trans-contextual model. Journal of Educational Psychology(95), 784-795.

18. Hagger, M. S., Chatzisarantis, N. L. D., \& Harris, J. (2006). The process by which relative autonomous motivation affects intentional behavior: Comparing effects across dieting and exercise behaviors. Motivation and Emotion, 30(4), 307-321.

19. Hair Jr, J. F., Black, W., C., Babin, B. J., \& Anderson, R. E. (2009). Multivariate Data Analysis (7th ed.). New Jersey: Prentice Hall.

20. Landry, J., B., \& Solomon, M. (2004). African American women's selfdetermination across the stages of change for exercise. Journal of Sport and Exercise Psychology(26), 457-469.

21. Lonsdale, C., Sabiston, C. M., Taylor, I. M., \& Ntoumanis, N. (2011). Measuring student motivation for physical education: Examining the psychometric properties of the Perceived Locus of Causality Questionnaire and the Situational Motivation Scale. Psychology of Sport and Exercise, 12(3), 284-292. doi: $\quad$ 10.1016/j.psychsport.2010.11.003 
22. Markland, D., \& Ingledew, D., K. (2007 ). Exercise Participation Motives. In M. S. Hagger \& N. L. D. Chatzisarantis (Eds.), Intrinsic Motivation and Self-Determination in Exercise and Sport: Human Kinetics.

23. McLachlan, S., \& Hagger, M. s. (2011). Do People Differntiate Between Intrinsic and Extrinsic Goals for Physical Activity? Journal of Sport and Exercise Psychology, 33, 273-288.

24. Patrick, H., \& Canevello, A. (2011). Methodological overview of a selfdetermination theory-based computerized intervention to promote leisuretime physical activity. Psychology of Sport and Exercise, 12, 13-19.

25. Quested, E., \& Duda, J. L. (2011). Perceived autonomy support, motivation regulations and the self-evaluative tendencies of student dancers. Journal of dance medicine \& science : official publication of the International Association for Dance Medicine \& Science, 15(1), 3-14.

26. Reeve, J., \& Deci, E. L. (1996). Elements within the comeptitive situation that affect intrinsic motivation Personality and Social Psychology Bulletin, $22,24-33$.

27. Ryan, \& Connel, J., P. (1989). Perceived locus of causality and internalization: Examining reason for acting in two domains. Contemporary Educational Psychology, 25, 54-67.

28. Ryan, \& Deci, E. L. (2007). Active Human Nature. In M. S. Hagger \& N. L. D. Chatzisarantis (Eds.), Intrinsic Motivation and Self-Determination in Exercise and Sport: Human Kinetics.

29. Ryan, Frederick, C. M., Lepes, D., Rubio, N., \& Sheldon, K. (1997). Intrinsic motivation and exercise adherence. Internaional Journal of Sport Psychology(28), 335-354.

30. Ryan, Koestner, R., \& Deci, E. L. (1991). Ego-involved persistence: When free-choice behavior is not intrinsically motivated. Motivation and Emotion, 15, 185-205.

31. Ryan, R. M., \& Deci, E. L. (2002). An Overview of Self-Determination Theory: An Organismic-Dialectical Perspective. In E. L. Deci \& R. M. Ryan (Eds.), Handbook of self-determination research (pp. 3-37). Rochester, N.Y.: University of Rochester Press.

32. Smith, A. L., Ntoumanis, N., Duda, J. L., \& Vansteenkiste, M. (2011). Goal striving, coping, and well-being: A prospective investigation of the self-concordance model in sport. Journal of Sport and Exercise Psychology, 33(1), 124-145.

33. Stanley, D. M., Cumming, J., Standage, M., \& Duda, J. L. (2012). Images of exercising: Exploring the links between exercise imagery use, autonomous and controlled motivation to exercise, and exercise intention and behavior. Psychology of Sport and Exercise, 13(2), 133-141. doi: 10.1016/j.psychsport.2011.10.002

34. Stuart, J. (2013). Enjoyment Based Motivation and Enjoyable Exercise Experience in Generation Y Sample: A Mixed Methods Approach. Master of Science Master, Georgia Southern University. 
35. Vallerand, R. J., \& Losier, G. F. (1999). An Integrative Analysis of Intrinsic and Extrinsic Motivation in Sport. Journal of Applied Sport Psychology, 11(1), 142-169.

36. Vansteenkiste, M., \& Deci, E. L. (2003). Competitively Contingent Rewards and Intrinsic Motivation: Can Losers Remain Motivated? Motivation and Emotion, 27(4), 273-299.

37. Verloigne, M., De Bourdeaudhuij, I., Tanghe, A., D'Hondt, E., Theuwis, L., Vansteenkiste, M., \& Deforche, B. (2011). Self-determined motivation towards physical activity in adolescents treated for obesity: An observational study. International Journal of Behavioral Nutrition and Physical Activity, 8. doi: 10.1186/1479-5868-8-97

38. Vlachopoulos, S. P., Ntoumanis, N., \& Smith, A. L. (2010). The basic psychological needs in exercise scale: Translation and evidence for crosscultural validity. International Journal of Sport and Exercise Psychology, 8(4), 394-412.

39. Wilson, K. B., \& Rodgers, W. M. (2004). The relationsship between perceived autonomy supprort, exercise regulations and behavioral inetntions in women. Psychology of Sport and Exercise(5), 229-242.

40. Wilson, K. B., Rodgers, W. M., \& Fraser, S. N. (2002). Examinig the psychometric properties of the behavioral regulation in exercise questionaire. Measurement in Physical Education and Exercise Science(6), $1-21$.

41. Wilson, P. M., Rodgers, W. M., Blanchard, C. M., \& Gessell, J. (2003). The Relationship between Psychological Needs, Self-Determined Motivation, Exercise Attitudes, and Physical Fitness. Journal of Applied Social Psychology, 33(11), 2373-2392.

Submitted: September 22, 2014 Accepted: December 9, 2014 